\title{
Posterior fossa aneurysms simulating tumours
}

\author{
W. F. MICHAEL \\ From the Department of Neurology, St. Bartholomew's Hospital, \\ and The National Hospital, Queen Square, London
}

SYNOPSIS Seven cases of aneurysm of the vertebral and basilar arteries, in which the clinical features suggested a diagnosis of posterior fossa tumour, are presented. Their clinical manifestations and the difficulties of diagnosis are discussed. These lesions may mimic cerebellopontine angle in tumours or brain-stem gliomas, or, less commonly, the picture is one of a compressive lesion at the foramen magnum. The need for vertebral angiography is emphasized. Exploratory surgery carries a high risk, and is to be avoided.

Posterior fossa aneurysms are uncommon lesions, and partly because of this continue to present considerable problems in diagnosis. With modern techniques of angiography, aneurysms of the vertebrobasilar system can usually be demonstrated unequivocally; however, vertebral angiography is still a procedure not without risk, and clinicians are rightly hesitant in advising this in circumstances where its relevance or helpfulness seems uncertain. This is particularly so where the clinical picture suggests a slowly expanding tumour, and the possibility of a vascular pathology may be overlooked.

A number of authors have discussed the difficulties of diagnosis of basilar aneurysms that have not bled and, even before the era of angiography, reports appeared of aneurysms found unexpectedly at operation or postmortem in patients supposedly suffering from posterior fossa tumours. Yaskin and Alpers (1944) collected a series of 21 such cases from the literature with symptoms of a mass lesion, and both they and Alajouanine et al. (1948) concluded that the diagnosis could not usually be made on clinical grounds alone. Denny-Brown and Foley (1952) felt that they could delineate a sufficiently clearcut syndrome resulting from arteriosclerotic basilar aneurysms to make angiography unnecessary; however, their six cases were elderly hypertensives with histories of sudden brainstem or posterior cerebral episodes, some of which subsequently improved and do not really fit in to the group under discussion. More recently Duvoisin and Yahr (1965) discussed the clinical features of posterior fossa aneurysm simulating tumours and also concluded that onl vertebral angiography can give a definitive $\infty$ diagnosis. Jannetta et al. (1966) claimed thas 운 aneurysms could be differentiated from none $-\vec{T}$ vascular tumours in this situation by pneumo encephalography, but as their criteria were selected with hindsight from two cases diagnose by vertebral angiography and necropsy re spectively, this was unconvincing.

This paper describes seven cases of large aneurysm of the vertebrobasilar system which simulated tumours, and discusses their clinical manifestations and management.

\section{SOURCES}

The case notes were studied of all patients seen at St. Bartholomew's Hospital and at the National Hospital, Queen Square, on whom the diagnosis of aneurysm of the vertebrobasilar system had been established angiographically. The earliest of these dated from 1953, and 46 cases were recorded up to 1972. Of these, 38 cases presented with subarachnoid haemorrhage and will not be further discussed. One further case with a small basilar aneurysm was also excluded as the clinical picture was clearly produced by a very large carotid aneurysm. The other seven cases are described below.

\section{CASE 1}

(SBH 510584.) A previously fit woman of 41 years was first seen in November 1970 complaining of 
double vision and was found to have a partial 6th nerve lesion. A carotid angiogram failed to show any abnormality. One year later she began complaining of deafness in the left ear. In August 1972 she was seen again having noticed a progressive weakness of the left side of the face for the past two months. Examination showed impairment of sensation on the left side of the face with an absent corneal reflex, a left 6th nerve palsy, and a lower motor neurone weakness of the left side of the face, but no objective hearing loss. The blood pressure was $130 / 70 \mathrm{mmHg}$. Plain radiographs of the skull showed some asymmetry of the internal auditory

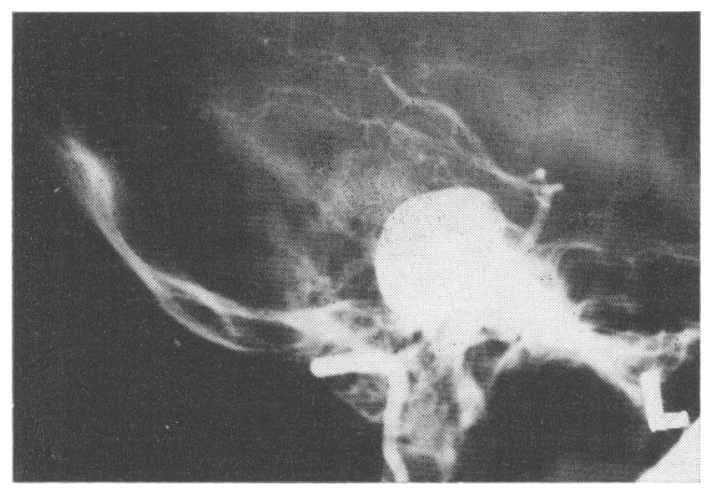

FIG. 1. Left vertebral angiogram, lateral view, in case 1, showing a large aneurysm of the basilar artery.

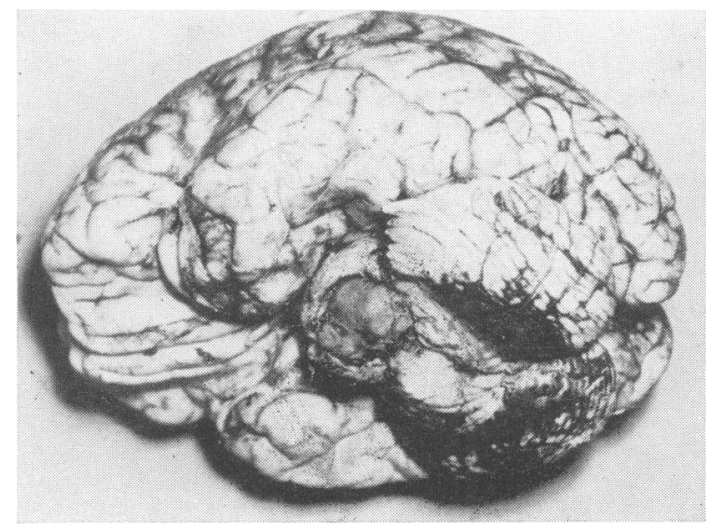

FIG. 2. The brain from case 1, as seen at postmortem, viewed from the side and below. Note the deep indentation of the brain-stem produced by the aneurysm. meati, the left appearing larger than the right. The cerebrospinal fluid (CSF) contained $88 \mathrm{mg} / 100 \mathrm{ml}$. protein. A pneumoencephalogram was reported as showing swelling of the brain-stem in both the lateral and PA views, with encroachment upon the pontine cistern and backward displacement of the 4th ventricle and aqueduct; the cerebellopontine angle cisterns on both sides were filled but were very narrow. It was felt that the diagnosis was a brainstem glioma and deep $x$-ray therapy was arranged. By way of confirmation before the start of treatment, a vertebral angiogram was done which demonstrated a large basilar aneurysm, shown in Fig. 1 . She remained well until six months later when she suddenly died from subarachnoid haemorrhage. The aneurysm was found at postmortem examination to be deeply indenting the brain-stem (Fig. 2).

CASE 2

(NHQS 87790.) This 67 year old woman was admitted in 1959. She had had hypertension for many years, and had been getting increasingly deaf, particularly on the right side. For nine months she had had severe occipital headaches made worse by coughing and sneezing. She gave a history of diplopia on looking to the right for about five months. A relative felt that there had been a gradual deterioration in mental function, and had observed a grand mal seizure a few months previously. On examination, there was evidence of impaired mental function, nystagmus on gaze to either side, a reduced corneal reflex on the right, and a right facial weakness. There was perceptive deafness, more on the right than the left. In the limbs, there were mild pyramidal tract signs and a terminal tremor mainly affecting the right arm and leg. The blood pressure was $180 / 110 \mathrm{mmHg}$ and the retinal vessels showed arteriosclerotic changes. It was felt that she presented a picture of scattered lesions, but with definite signs pointing to a posterior fossa lesion, and that these features could best be explained by a basilar aneurysm with arteriosclerotic changes elsewhere. The CSF contained $100 \mathrm{mg} / 100 \mathrm{ml}$. protein. A pneumoencephalogram showed a small lesion filling the right cerebellopontine angle, and a vertebral angiogram showed a tortuous left vertebral artery with aneurysmal dilatation of the basilar artery. The patient was not disturbed by these investigations. She was transferred to another hospital and died three months later.

\section{CASE 3}

(NHQS A17599.) This 58 year old woman was first admitted to the National Hospital in April 1964 
having had a subarachnoid haemorrhage producing coma without localizing signs. Bilateral carotid angiograms and a right vertebral angiogram were negative. She was readmitted in June 1967 complaining of occipitocervical headaches for six months, progressive weakness of the left arm and leg, and difficulty in distinguishing temperature with the right hand. Examination then revealed tenderness in the upper part of the neck, more on the left than the right. There was severe weakness of upper motor neurone type in the left arm and leg, and impairment of temperature sensation on the right side below the level of the 4th cervical dermatome. A clinical diagnosis of upper cervical cord compression producing a Brown-Séquard syndrome, possibly due to cervical spondylosis or spinal cord tumour was made. Plain radiographs of the skull were normal and plain radiographs of the cervical spine showed spondylotic changes only. A myelogram demonstrated a filling defect of $2 \mathrm{~cm}$ at the level of the foramen magnum on the left side. The CSF protein was $167 \mathrm{mg} / 100 \mathrm{ml}$. A left vertebral angiogram showed this to be an aneurysm. She was treated conservatively but subsequently she suffered increasing left-sided weakness and pain on movement of her neck, and died six months later.

\section{CASE 4}

(NHQS A24214.) This man, aged 58 years, was first seen in May 1965 with a year's history of increasing apathy and forgetfulness. Ten days before admission he woke with a severe headache, followed the next day by some weakness of his right arm and difficulty with speech which improved after about two days. Examination showed a moderately severe dementia, slight right facial weakness, and minimal pyramidal tract signs in the right arm and leg. His blood pressure was normal. Skull radiograph and electroencephalogram (EEG) were normal and a pneumoencephalogram showed a large mid-line surprasellar space occupying lesion. The CSF contained 20 lymphocytes per cu. $\mathrm{mm}$ and protein $90 \mathrm{mg} / 100 \mathrm{ml}$. Bilateral carotid angiography showed two small aneurysms, one on each internal carotid artery, and a vertebral arteriogram demonstrated a large aneurysm at the termination of the basilar artery which was thought to be causing the filling defect seen on the pneumoencephalogram. It was felt that this lesion was causing some intermittent obstruction to the flow of CSF, thus contributing to the dementia. The recent headache and transient weakness were thought to be the result of a slight leakage of blood from the aneurysm. He was readmitted two years later for increasing dementia and incoordination, now with bilateral pyramidal tract signs. An intra- thecal isotope scan suggested some degree of obstructive hydrocephalus. Repeat pneumo-encephalogram showed that the basilar aneurysm was larger than previously, and there was evidence of increasing hydrocephalus due to obstruction at the foramina of Monro and also at the tentorial hiatus. A shunting operation to reduce the intraventricular pressure produced a considerable subsequent improvement in his walking and balance and possibly also in his intellectual function. However, a year later he suddenly became stuporose and died. Necropsy showed subarachnoid and intraventricular haemorrhage, and an aneurysm of the upper part of the basilar artery indenting the third ventricle and extending to the foramen of Monro.

\section{CASE 5}

(NHQS A28382.) This 60 year old woman was first admitted to the National Hospital in January 1966, when she gave a six month history of headaches. Four months beforehand she had noticed drooping of the left eyelid and double vision on upward gaze. The ptosis quickly became complete and waso accompanied by a severe throbbing pain in the region of the left orbit. The ptosis and the diplopia had partially cleared by the time she was admitted. On examination, there was a partial left 3rd nerve palsy. She was moderately hypertensive with a blood pressure of $200 / 110 \mathrm{mmHg}$. A left carotid angiogrant showed an area of dilatation in the region of the anterior communicating artery and also some irregularity of the origin of the internal carotid artery in the neck. It was felt that the 3rd nerve palsy was the result of arteriosclerosis rather than a local gross vascular abnormality. She was discharged and made a steady improvement, with the ocular palsy finally disappearing. However in April 1967 she had an exacerbation of the left frontal headache which extended into the left side of the neck and inside the ear on that side. With this, the left eyelid gradually drooped more and then closed completely. On examination there was a complete left 3rd nerve palsy and bilateral extensor plantar responses. A left vertebral angiogram showed an aneurysm arising from the terminal part of the basilar artery and projecting posteriorly. Once again it was not felt that surgical intervention was indicated.

\section{CASE 6}

(NHQS A29677.) This 61 year old man was admitted to the National Hospital in March 1966 with a history of unsteadiness on standing for 18 months. For one year he had had increasing deafness in the left ear with tinnitus. He had noticed some difficulty 
in swallowing for the past six months and occasionally early morning headaches. For four months there had been a progressive weakness of the legs, such that he was now having difficulty in getting out of a chair. Examination showed early bilateral papilloedema. There was marked nystagmus in all directions of gaze. The left corneal reflex was depressed and he had impaired pain sensation over the first division of the left trigeminal nerve, though appreciation of light touch seemed unimpaired. In addition, there was evidence of lesions of the left 8th, 9th, 10th, and 12th cranial nerves, the last mentioned producing wasting and fasciculation of the tongue on that side. In the limbs, there was a mild right hemiparesis and left sided cerebellar signs. The blood pressure was $180 / 100 \mathrm{mmHg}$.

A diagnosis of left cerebellopontine angle tumour was made; an acoustic neuroma seemed possible but the lack of a facial nerve lesion was unusual, and this lesion was clearly a very long one to involve the 12th nerve. It was decided to proceed straight to a ventriculogram, and this revealed a large mass lying in the left cerebellopontine angle. Surgical exploration showed this to be a large aneurysm of the vertebral artery with extensive intramural thrombosis. Nothing further was done and the patient made an uneventful recovery. However, he died nine months later in another hospital, the cause being given as thrombosed vertebral aneurysm. No necropsy was carried out.

\section{CASE 7}

(NHQS A52569.) This was a man aged 59 years who presented to the National Hospital in February 1970. For the past 10 years he had suffered from headaches, and three months before admission he developed a progressive unsteadiness of gait and difficulty in swallowing. On admission, he had nystagmus on lateral and upward gaze, mild bilateral 7 th nerve weakness, bilateral palatal weakness with diminished pharyngeal sensation, and atrophy and fasciculation of both sides of the tongue. Gait was severely ataxic and the left plantar response was extensor. It was felt that he was suffering from an infiltrating space occupying lesion in the posterior fossa, possibly a pontine glioma. A lumbar puncture showed a CSF protein of $400 \mathrm{mg} / 100 \mathrm{ml}$. Ventriculography revealed a filling defect in the floor of the 4th ventricle. The posterior fossa was therefore explored; the lower part of the medulla and upper part of the spinal cord were markedly expanded and displaced posteriorly, apparently due to an intramedullary lesion. Further inspection showed an extracerebral mass extending upwards into the cerebellopontine angle. Needling this failed to produce any fluid, and an incision into it showed the contents to be a reddish brown material. A brisk arterial haemorrhage then occurred and it was then realized that the lesion was an aneurysm, largely filled with thrombus. The bleeding was eventually stopped and the feeding vessel to the aneurysm clipped. Bilateral vertebral angiograms were done soon after the operation, when it appeared that the clips were effective as the aneurysm was not visualized. The patient's condition remained critical, and he died three days later. At postmortem examination an enormous aneurysm was found arising from the left vertebral artery, equivalent in bulk to the medulla. The patient's demise was attributed to brain-stem infarction.

\section{DISCUSSION}

These cases are generally in accord with those of earlier series, both in their clinical features and in the difficulties experienced in coming to a correct diagnosis. As Yaskin and Alpers (1944) pointed out, a considerable variety of symptoms and signs is to be expected in view of the large number of important structures related to the vertebral and basilar arteries, but several syndromes seem to result fairly frequently from posterior fossa aneurysms. In the 21 cases of aneurysm simulating a mass lesion reviewed by Yaskin and Alpers (1944), palsies of cranial nerves 3 to 10 , ataxia and long tract signs, and an organic mental syndrome all occurred, and similar features were seen in the smaller series of Alajouanine et al. (1948) and Duvoisin and Yahr (1965). Particularly commonly involved were the 7th and 8th cranial nerves, often producing a picture resembling that of a cerebellopontine angle tumour. Trillet et al (1970) describe a typical case of this sort. In the present series, cases 1,2 , and 6 all had signs pointing to a lesion in this location, though case 2 also showed evidence of hypertension and arteriosclerosis, to which were attributed the intellectual deterioration and the grand mal fit. Case 6 had much more extensive cranial nerve involvement than would be usual with an acoustic neuroma. Lower cranial nerve palsies are not uncommon in the literature, but it is interesting that both cases 6 and 7 showed wasting of the tongue as involvement in earlier series seems more usually to have extended only down to the 10 th nerve. Incoordination, ataxia, and pyra- 
midal tract signs, either alone or with cranial nerve palsies, are frequent and point to involvement of the cerebellum and brain-stem. Symptoms and signs of raised intracranial pressure were seen only in case 6 , but are well documented in earlier series; case 4 , however, with intermittent obstructive hydrocephalus, is much more unusual.

\section{TABLE 1}

INCIDENCE OF HEADACHES AND CSF PROTEIN LEVELS IN PRESENT SERIES

\begin{tabular}{lll}
\hline Case & \multicolumn{1}{c}{ Headaches } & \multicolumn{1}{c}{$\begin{array}{c}\text { CSF protein } \\
(\mathrm{mg} / 100 \mathrm{ml} .)\end{array}$} \\
\hline 1 & No & 88 \\
2 & Severe occipital & 100 \\
3 & Intermittent & 167 \\
4 & Sudden headache at start & 90 \\
& of illness only & Not done \\
6 & Yes & Not recorded \\
7 & Occasional early morning & 400 \\
& Yes & \\
\hline
\end{tabular}

Usually therefore the physical signs are those of a cerebellopontine angle mass or brain-stem compression. Much less common is the picture of a lesion at the level of the foramen magnum or below, illustrated in the present series by case 3 . Yaskin and Alpers (1944) report one such case of their own who had both brain-stem and spinal cord signs and include one other case from the literature. Perhaps the most fully described example of this syndrome is the case of Symonds et al. (1937) in which a vertebral aneurysm produced compression of the spinal cord at the foramen magnum (their case 6).

The anatomical site of these lesions is generally clear and it is defining the pathology that tends to present the problem. It will be noticed that case 2 was the only one of this series in which the diagnosis of basilar aneurysm was made on purely clinical grounds, but a pneumoencephalogram was still thought advisable to exclude a small tumour in the cerebellopontine angle. In case 3 , even with the clue provided by the previous subarachnoid haemorrhage, the diagnosis of vertebral aneurysm was not clearly anticipated. Clues to the aneurysmal nature of the tumour emphasized by earlier authors have been an episodic history, suboccipital headache and nuchal pain aggravated by movement of the head (Yaskin and Alpers), and elevation of the CSF protein with or without xanthochromia (Duvoisin and Yahr). Table 1 shows the incidence of headaches and the CSF protein levels in the present series; the headaches of case 6 were presumably those of raised intracranial pressure, and otherwise only in case 2 were the headaches helpful diagnostically. The CSF protein on the other hand was elevated in all cases in which it was recorded, although, of course, this also is a non-specific finding.

In cases 6 and 7, the true nature of the problem came to light only as a result of surgical exploration. In case 6 the patient made a satisfactory recovery, but case 7 died soon after the operation. There seems no doubt that exploration in patients who prove to have posterior fossa aneurysms is highly dangerous; this was pointed out by Alajouanine et al. (1948), both of whose cases were explored surgically and died withiro three days, while of the seven cases from the

TABLE 2

LENGTH OF HISTORY AND FINAL OUTCOME IN PRESENT SERIE

\begin{tabular}{|c|c|c|}
\hline Case & Length of history till admission & $\begin{array}{l}\text { Progress after } \\
\text { admission }\end{array}$ \\
\hline 1 & $\begin{array}{l}\text { Twenty-one months } 6 \text { th nerve } \\
\text { palsy }\end{array}$ & $\begin{array}{l}\text { Died six months } \\
\text { later }\end{array}$ \\
\hline 2 & $\begin{array}{l}\text { Nine months headaches and } \\
\text { diplopia. Many years deafness }\end{array}$ & $\begin{array}{l}\text { Died three months } \\
\text { later }\end{array}$ \\
\hline 3 & $\begin{array}{l}1964 \text { subarachnoid haemorrhage; } \\
1967 \text { six months headaches, one } \\
\text { month hemiparesis }\end{array}$ & $\begin{array}{l}\text { Died six months } \\
\text { after admission }\end{array}$ \\
\hline 4 & Two years dementia & $\begin{array}{l}\text { Died one year later } \\
\text { of subarachnoid } \\
\text { haemorrhage }\end{array}$ \\
\hline 5 & Two years headaches and diplopia & \\
\hline 6 & $\begin{array}{l}\text { Eighteen months unsteadiness and } \\
\text { deafness }\end{array}$ & $\begin{array}{l}\text { Died nine months } \\
\text { later of 'throm- } \\
\text { bosed vertebral } \\
\text { aneurysm' }\end{array}$ \\
\hline 7 & $\begin{array}{l}\text { Three months unsteadiness and } \\
\text { difficulty swallowing }\end{array}$ & $\begin{array}{l}\text { Died three days } \\
\text { post-op. }\end{array}$ \\
\hline
\end{tabular}

literature that they reviewed, four were operated on and all succumbed within a few hours. Death was equally rapid in Symonds and Meadows's case. Case 7 also illustrates another grave disadvantage of posterior fossa surgery, in that, even by direct observation, it may prove difficult 
or impossible to discover with certainty the nature of the lesion, because of the distortion of the anatomy and sometimes from the tendency of aneurysms to burrow deep into nervous tissue. This last feature is visible in Fig. 2. This problem was encountered in both of the cases of Alajouanine et al. (1948), the second case of Dandy (1944), and a case described by Guillain et al. (1930), in all of which the aneurysm was either not seen or not correctly identified, and the diagnosis was made at the necropsies that followed soon afterwards.

However, although surgery is clearly highly unsatisfactory as a means of diagnosing vertebrobasilar aneurysms, this is not necessarily to say that it may not be successful as a means of treating those patients already known to be suffering from these lesions, as a planned procedure. With advances in anaesthetic and surgical technique this may become more feasible, and Sundt et al. (1972) report the successful removal of a large basilar aneurysm under conditions of profound hypothermia and circulatory arrest. Jannetta et al. (1966) also describe the ligation of a vertebral aneurysm without mishap, apparently without the use of special techniques.

The prognosis of these large vertebrobasilar aneurysms seems to be poor. Table 2 shows the length of history of each of the present cases and the final outcome, and these results correspond to earlier ones. Only one of the five cases described by Duvoisin and Yahr (1965) was alive two years after the onset of symptoms. In contrast with this, Troupp (1971) found that, out of 20 cases presenting with subarachnoid haemorrhage, only eight had died 52 months after diagnosis. It appears therefore that basilar aneurysms that present with pressure symptoms have no better prognosis than those that come to light because of bleeding.

In conclusion, it is clear that large vertebrobasilar aneurysms are dangerous lesions. They are difficult or impossible to distinguish from other space occupying lesions on clinical grounds, and vertebral angiography is the only certain way of making the diagnosis. This is essential if surgery is contemplated.

The author wishes to thank Dr. J. W. Aldren Turner for permission to publish case 1, and for much helpful advice and discussion. Permission from the Medical Committee of the National Hospital to publish cases 2 to 7 is gratefully acknowledged. Dr. G. du Boulay greatly facilitated this study by kindly making available his private radiological records. Dr. H. C. Grant of the Department of Neuropathology, Middlesex Hospital, carried out the postmortem examination on case 1 , and generously provided the photograph for Fig. 2. Dr. A. P. Hopkins kindly read the manuscript and provided much helpful discussion.

\section{REFERENCES}

Alajouanine, T., Le Beau, J., and Houdart, R. (1948). La symptomatologie tumorale des volumineaux anévrysmes des artères vertébrales et basilaires. Revue Neurologique, $\mathbf{8 0}$, 321-337.

Dandy, W. E. (1944). Intracranial Arterial Aneurysms. Comstock: Ithaca, N.Y.

Denny-Brown, D., and Foley, J. M. (1952). The syndrome of basilar aneurysm. Transactions of the American Neurological Association, 77, 30-34.

Duvoisin, R. C., and Yahr, M. D. (1965). Posterior fossa aneurysms. Neurology (Minneap.), 15, 231-241.

Guillain, G., Schmite, P., and Bertrand, I. (1930). Anévrysme du tronc basilaire ayant déterminé la symptomatologie d'une tumeur de l'angle ponto-cérébelleux. Revue Neurologique, 1, 795-802.

Jannetta, P. J., Hanafee, W., Weidner, W., and Rosen, L. (1966). Pneumoencephalographic findings suggesting aneurysm of the vertebral-basilar junction. Journal of Neurosurgery, 24, 530-535.

Sundt, T. M., Jr., Pluth, J. R., and Gronert, G. A. (1972). Excision of giant basilar aneurysm under profound hypothermia. Report of case. Mayo Clinic Proceedings, 47, 631634.

Symonds, C. P., Meadows, S. P., and Taylor, J. (1937). Compression of the spinal cord in the neighbourhood of the foramen magnum. Brain, 60, 52-84.

Trillet, M., Eyssette, M., and Schott, B. (1970). Histoire naturelle d'un anévrysme de l'angle ponto-cérébelleux gauche. Journal de Médecine de Lyon, 51, 877-882.

Troupp, H. (1971). The natural history of aneurysms of the basilar bifurcation. Acta Neurologica Scandinavica, 47, 350-356.

Yaskin, H. E., and Alpers, B. J. (1944). Aneurysm of the vertebral artery. Report of a case in which the aneurysm simulated a tumor of the posterior fossa. Archives of Neurology and Psychiatry (Chic.), 51, 271-281. 